\title{
Quantifying into Question Acts
}

\author{
Manfred Krifka \\ University of Texas at Austin
}

\section{Quantifiers in Questions}

Quantified NPs in questions lead to three distinct interpretations. The narrowscope reading of (1) requires answers like (2.a), the functional reading, answers like (2.b), and the pair-list reading, answers like (2.c).

(1) Which dish did every boy make?

(2) a. (Every boy made) pasta.

b. (Every boy made) his favorite dish.

c. $\mathrm{Al}$ (made) the pasta, Bill the salad, and Carl the pudding.

There are reasons for distinguishing these three readings that relate to grammatical properties of the question itself, and not to their answers. First, in certain syntactic configurations pair-list readings are absent (cf. (3), (4)). Second, many quantifiers do not allow for pair-list readings (cf. (5), (6)).

(3) Which boy ${ }_{1}\left[\mathrm{t}_{1}\right.$ [made every dish]]?

(4) a. Bill.

b. \#The boy that likes it best.

c. \#The pasta (were made by) Al, the salad, (by) Bill, and the pudding, (by) Carl.

(5) Which dish did most/several/a few/no boys make?

(6) a. Pasta.

b. Their favorite dish.

c. \#Al the pasta, and Bill the salad.

This article will try to explain why pair-list readings are possible with universal quantifiers but not with others. I will argue that those readings involve conjoined question acts. While conjunction of speech acts is a natural concept, other Boolean operations aren't, and hence quantifiers that are not generalized conjunctions cannot scope over question acts. But let me first turn to existing approaches to pair-list readings.

\section{Approaches to Pair-List readings}

\subsection{Quantifiying into Questions}

There are three major approaches to pair-list interpretations (cf. the overviews in Szabolcsi (1997) and Pafel (1999)). For Hamblin (1973), a question denotes the set of the meanings of its congruent answers; for Karttunen (1977), the set of true congruent answers. In (7), this is given by a characteristic function. Pair-list interpretations involve quantification into such question meanings, cf. (8).

$$
\begin{aligned}
& \text { Which dish did Bill make? } \\
& \lambda \mathrm{p} \exists \mathrm{x}\left[\mathrm{DI}(\mathrm{x}) \wedge\left({ }^{\mathrm{p} p}\right) \wedge \mathrm{p}={ }^{\wedge}[\mathrm{MA}(\mathrm{x})(\mathrm{B})]\right]
\end{aligned}
$$


Which dish did every boy make?

'For every boy y: Which dish did y make?'

But it is difficult to express the paraphrase in (8). It certainly cannot be (9.a), which is ill-formed, as the expression following " $\rightarrow$ " is not of the sentential type $t$. It also cannot be (9.b), which is fine as far as the types go, but which gives us the wrong reading: Only if every boy made the same dish does (9.b) describe a non-empty set of propositions, and this is certainly not presupposed by the pair-list reading of (8). (But see section 6 for another option not discussed by Karttunen).
a. $* \forall y\left[\right.$ Bо $(y) \rightarrow \lambda p \exists x\left[\operatorname{DI}(x) \wedge{ }^{\vee} \mathrm{p} \wedge \mathrm{p}={ }^{\wedge}[\mathrm{MA}(\mathrm{x})(\mathrm{y})]\right]$
b. $\# \lambda \mathrm{p} \forall \mathrm{y}\left[\mathrm{BO}(\mathrm{y}) \rightarrow \exists \mathrm{x}\left[\operatorname{DI}(\mathrm{x}) \wedge \wedge^{\vee} \mathrm{p} \wedge \mathrm{p}={ }^{\wedge}[\mathrm{MA}(\mathrm{x})(\mathrm{y})]\right]\right.$

In view of this problem, Karttunen proposes that root questions are embedded by a silent embedding verb, following the performative analysis of Ross (1970). If the quantifier outscopes that verb, then we get the right representation:

a. Which dish did every boy make?

'For every boy $\mathrm{x}$, I ask you which dish $\mathrm{x}$ made.'

b. $\forall \mathrm{y}\left[\mathrm{BO}(\mathrm{y}) \rightarrow \operatorname{ASK}\left(\mathrm{I}, \mathrm{YOU}, \lambda \mathrm{p} \exists \mathrm{x}\left[\mathrm{DI}(\mathrm{x}) \wedge{ }^{\vee} \mathrm{p} \wedge \mathrm{p}={ }^{\wedge}[\mathrm{MA}(\mathrm{x})(\mathrm{y})]\right]\right)\right]$

While the proposal I will defend below is inspired by this solution, there are problems with this particular implementation - the usual problems of the performative hypothesis, as discussed in Levinson (1983), pp. 247-263. To mention just one: A question like Which dish did Al make?, analyzed as I ask you which dish did Al make?, would necessarily be true, just like other performative sentences.

\subsection{Quantifiers as Domain Restrictors}

The theory of Groenendijk \& Stokhof $(1984,1989)$ is similar to Hamblin's or Karttunen's, insofar questions denote sets of possible worlds. But it differs insofar they denote sets of equivalence classes (partitions) of the set of possible worlds. More precisely, a question denotes an equivalence relation between possible worlds that corresponds to a partition. Example:

$$
\begin{aligned}
& \text { Which dish did Al make? } \\
& \lambda j \lambda i[\lambda x[D I(i)(x) \wedge M A(i)(x)(B)]=\lambda x[D I(j)(x) \wedge M A(j)(x)(A)]]
\end{aligned}
$$

This is a relation between possible worlds $\mathrm{j}$ and $\mathrm{i}$ that obtains iff the dishes that Bill made in $\mathrm{i}$ are the dishes that Bill made in $\mathrm{j}$. This equivalence relation corresponds to a partition of possible worlds into disjoint sets such that for all possible worlds within one set, $\mathrm{Al}$ made the same dishes. For example, if there are two dishes, pasta and salad, then (11) would contain the 4 cells (I have illustrated two worlds $\mathrm{j}$, $i$ that stand in the equivalence relation and highlighted one equivalence class):

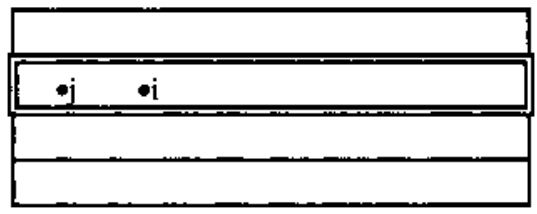

Al made pasta and salad

Al made pasta

Al made salad

Al made nothing 
The way how the equivalence relations are construed enables us to represent quantification into questions like in (9.a), but now without type conflict:

$$
\begin{aligned}
& \text { Which dish did every boy make? } \\
& \lambda \mathrm{j} \lambda \mathrm{i} \forall \mathrm{y}[\mathrm{BO}(\mathrm{j})(\mathrm{y}) \rightarrow \lambda \mathrm{x}[\operatorname{DI}(\mathrm{i})(\mathrm{x}) \wedge \mathrm{MA}(\mathrm{i})(\mathrm{x})(\mathrm{y})]=\lambda \mathrm{x}[\mathrm{DI}(\mathrm{j})(\mathrm{x}) \wedge \mathrm{MA}(\mathrm{j})(\mathrm{x})(\mathrm{y})]]
\end{aligned}
$$

This relation between possible worlds $j$ and $i$ obtains iff for every boy $x$ (in $j$ ), the dishes that $x$ made in $i$ are the dishes that $x$ made in $j$. In terms of partitions, this corresponds to the collection of disjoint sets such that for every boy $\mathrm{x}$, the dishes that $\mathrm{x}$ made are the same for all possible worlds within one set. If there is more than one boy in the model, this will result in a more fine-grained partition than the one induced by (11); notice that (13) is a more specific question than (11). With two dishes and two boys we have $4 \times 4=16$ cells, as indicated on the left side of (14) (ignoring world knowledge that dishes are typically made by one person):

(14)

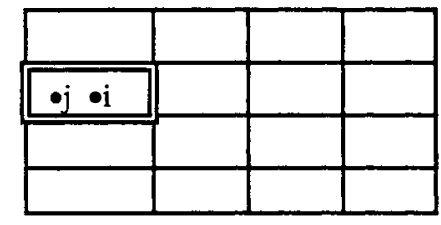

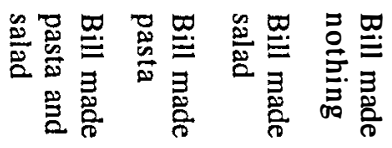

Which dish did a boy make?
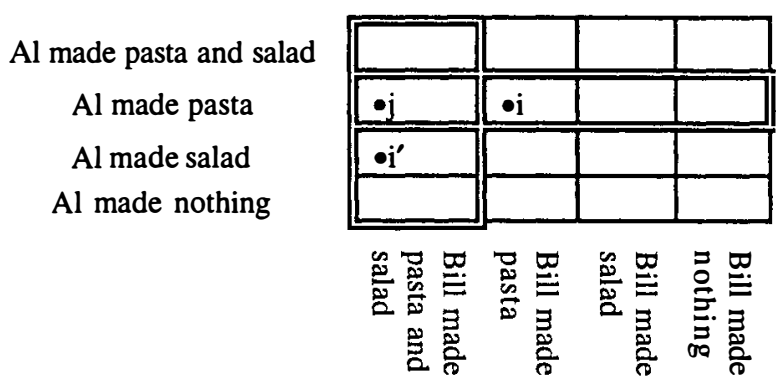

Groenendijk \& Stokhof argue that this solution, as it stands, has one drawback: It does not work for quantifiers other than universal quantifiers. Take quantifying an existential NP into a question:

Which dish did two boys make?

$$
\lambda j \lambda i \exists_{2} y[B O(j)(y) \wedge \lambda x[D I(i)(x) \wedge M A(i)(x)(y)]=\lambda x[D I(j)(x) \wedge M A(j)(x)(y)]]
$$

This relation holds between worlds $j$ and $i$ iff there are two boys $y^{\prime}, y^{\prime \prime}$ (in $j$ ) such that the dishes that $y^{\prime}$ made in $i$ are the same as the ones that $y^{\prime}$ made in $j$, and the dishes that $y^{\prime \prime}$ made in i are the same as the ones that $y^{\prime \prime}$ made in $j$. It is an equivalence relation in case there are exactly two boys in the model. In case there are, say, three boys, the selection of any two boys will lead to a distinct equivalence relation, and their union is not an equivalence relation. To see this, consider the simpler case (16) in a model with two boys.

Which dish did a boy make?

$\lambda \mathrm{j} \lambda \mathrm{i} \exists \mathrm{y}[\mathrm{BO}(\mathrm{j})(\mathrm{y}) \wedge \lambda \mathrm{x}[\operatorname{DI}(\mathrm{i})(\mathrm{x}) \wedge \mathrm{MA}(\mathrm{i})(\mathrm{x})(\mathrm{y})]=\lambda \mathrm{x}[\operatorname{DI}(\mathrm{j})(\mathrm{x}) \wedge \mathrm{MA}(\mathrm{j})(\mathrm{x})(\mathrm{y})]]$

Consider the right-hand side of (14). The worlds $\mathrm{j}$ and $\mathrm{i}$ stand in the relation (16), and sodo $j$ and $i^{\prime}$, but $i$ and $i^{\prime}$ don't. Hence it is not an equivalence relation (it is not transitive), and we don't get a partition (some cells overlap).

The fact that, with quantification into questions, only universal quantifiers lead to an equivalence relation, and hence to a true question, might be seen as a welcome consequence because questions like (15) are considerably more contrived than question like (13). But Groenendijk \& Stokhof do not distinguish between the naturalness of these questions, and hence have to account for why questions like 
(15) are possible. The reading that is available for such questions they call choice reading; it can be paraphrased as follows:

Which dish did two boys make?

'Pick out two boys, and tell me which dish did everyone of them make?'

Notice that the embedded question in the paraphrase contains a universal quantifier, which distributes over the two boys that were picked out. In order to express this idea for root questions, we must first type-lift the question (here illustrated with the simpler case of a singular indefinite NP):

$$
\begin{aligned}
& \text { Which dish did a boy make? } \\
& \lambda \mathrm{Q} \exists \mathrm{y}[\mathrm{BO}(\mathrm{j})(\mathrm{y}) \wedge \\
& \mathrm{Q}(\mathrm{j})(\lambda \mathrm{j} \lambda \mathrm{i}[\lambda \mathrm{x}[\mathrm{DI}(\mathrm{i})(\mathrm{x}) \wedge \mathrm{MA}(\mathrm{i})(\mathrm{x})(\mathrm{y})]=\lambda \mathrm{x}[\operatorname{DI}(\mathrm{j})(\mathrm{x}) \wedge \mathrm{MA}(\mathrm{j})(\mathrm{x})(\mathrm{y})]])]
\end{aligned}
$$

Here, the unbound $j$ stands for the actual world. We get a set of question meanings $\mathrm{Q}$, one for each selection of $\mathrm{y}$. If there are two boys, $\mathrm{Al}$ and Bill, then (18) applies to the two questions, 'which dish did $\mathrm{Al}$ make?' and 'which dish did Bill make?'.

To arrive at a uniform treatment of wide-scope quantifiers, Groenendijk \& Stokhof assume that questions select for the witness set of a quantifier (see Barwise \& Cooper (1981) for this notion). Universal quantifiers have a unique witness set; the witness set of every boy is the set of all boys. Other quantifiers have non-unique witness sets; the witness sets of two boys are the sets that consist of two boys, and the witness sets of most boys are the sets that consist of more than half of the boys. Groenendijk \& Stokhof interpret quantification into questions as in (19), where QP stands for an arbitray quantifier phrase:

$$
\begin{aligned}
& \text { Which dish did } Q P \text { make? } \\
& \lambda Q \exists W[W \text { is a witness set of } Q P \wedge \\
& Q(j)(\lambda j \lambda i[\lambda x \in W[D I(i)(x) \wedge M A(i)(x)(y)]=\lambda x \in W[D I(j)(x) \wedge M A(j)(x)(y)]])]
\end{aligned}
$$

The witness set of a quantifier serves as the restriction for the $w h$-variable, $\mathrm{x}$, that is, quantifiers are analyzed as domain restrictors. For unique witness sets $Q$ applies only to one question, in contrast to non-unique ones.

Groenendijk \& Stokhof's insight that only universal quantifiers lead to a unique question meaning is an interesting consequence of their framework. As mentioned, this may explain why universal quantifiers easily scope out of questions, in contrast to other quantifiers, as observed in (1) vs. (5). We do not need type-lifting of questions for universal quantifiers, but we do need it for nonuniversal quantifiers. However, Groenendijk \& Stokhof then develop techniques that allow for equal reatment for all quantifiers, which obliterates the distinction between universal and other quantifiers. They also have to resort to a special interpretation of quantifiers when quantifying into questions, which is suspicious.

\subsection{Pair-List Questions as Functional Questions}

Engdahl (1985) has developed an analysis of pair-list interpretations in which they are not analyzed as involving quantification into questions at all, but rather functional readings. This analysis has been further explored by Chierchia (1993). 
Functional readings are analyzed as involving quantification over a function. In Hamblin's framework, this amoun to the analysis given in (20). The answer then specifies that function, e.g. by his favorite dish, which maps male individuals to their favorite dish, cf. (21.a). This is an intensional specification of a function. A pair-list answer is just another way of specifying a function, namely extensionally, by a set of pairs, cf. (21.b).

(20) Which dish did every boy make?

$\lambda \mathrm{p} \exists \mathrm{f}[\operatorname{range}(\mathrm{f})=\mathrm{DI} \wedge \mathrm{p}=\wedge \forall \mathrm{y}[\mathrm{BO}(\mathrm{y}) \rightarrow \mathrm{MA}(\mathrm{f}(\mathrm{y}))(\mathrm{y})]]$

'Which $\mathrm{f}$ (a function to dishes) is such that every boy y made $\mathrm{f}(\mathrm{y})$ ?'

(21) a. His favorite dish. $\mathrm{f}=\lambda \mathrm{x}$ [THE FAVORITE DISH OF $\mathrm{x}]$

b. Al the pasta, Bill the salad, and Carl the pudding. $\mathrm{f}=\{\langle\mathrm{A}$, PASTA $\rangle,\langle\mathrm{B}, \mathrm{SALAD}\rangle,\langle\mathrm{C}, \mathrm{PUDDING}\rangle\}$

Crucially, quantification over a function $\mathrm{f}$ enables us to treat pair-list interpretations as involving a narrow-scope quantifier. Of course, this is why such Skolem functions were proposed in the first place; they generally allow us to replace wide-scope universals, as in $\forall x \exists y[R(x, y)]$, by narrow-scope ones, as in $\exists f \forall x[R(x, f(x))]$.

Chierchia argues that this analysis can explain why (3) is bad under both the functional interpretation and the pair-list interpretation. It leads to a Weak Crossover violation, which he interprets as involving a configuration in which a quantifier over a variable $\mathrm{x}$ first binds a function applied to $\mathrm{x}$, and then $\mathrm{x}$ itself. I illustrate two standard cases of weak crossover violation in (22) and (23), and the violation in functional / pair-list readings in (24).

*Which boy ${ }_{\mathrm{i}}$ does his mother love? $^{\mathrm{i}}$ ?

'For which boy x: mother(x) loves $\mathrm{x}$ ?'

* His 1 mother loves every boy .

'For every boy $\mathrm{x}$, mother( $\mathrm{x})$ loves $\mathrm{x}$.'

Which boy made every dish?

*'For which $\mathrm{f}$ (a function to boys): for every dish $\mathrm{x}, \mathrm{f}(\mathrm{x})$ made $\mathrm{x}$.'

But there are problems with this analysis (cf. also Beghelli 1997). First, quantifiers based on the determiner each allow for pair-list readings, cf. (25), but they do in standard Weak Crossover configurations, cf. (26).

Q: Which boy made each dish?

$\mathrm{A}$ : The pasta was made by $\mathrm{Al}$, the salad by Bill, and the pudding by Carl.

* His $_{\mathrm{i}}$ mother loves each boy . $_{\mathrm{i}}$

Another problem is that the Weak Crossover effect vanishes with certain complement questions (Szabolcsi (1993, 1997)):

(27) I know which boy made every dish.

'For every dish x, I know which boy made x.'

Also, many quantifiers allow for functional readings but not for pair-list readings (Liu (1990), Chierchia (1993)). Recall that this was a reason why we distinguished between pair-list readings and functional readings in the first place. 
(28) Q: Which dish did most boys make?

A: Their favorite dish.

(29) Q: Which dish did no boy make?

A: His least favorite dish.

To be sure, Chierchia does not completely identify pair-list readings with functional readings. But the problems for his approach listed here obtain also in the refined version of his theory.

\section{A New Approach: Conjoined Question Acts}

\subsection{Pair-List Questions as Conjoined Questions}

I would like to suggest that pair-list intepretations are to be analyzed as conjoined questions. That is, a pair-list question like (30) that uses a quantifier, every boy, is short for a conjoined question like (31) (if there are three boys, Al, Bill and Carl), just as Every boy came is short for Al came and Bill came and Carl came.

Which dish did every boy make?

Which dish did $\mathrm{Al}$ make, which dish did Bill make, which dish did Carl make?

These questions in their pair-list readings allow for exactly the same answers. Generally, the answer to a conjoined question is a conjunction of the answers to each conjunct.

$\mathrm{Al}$ (made) the pasta, Bill the salad, and Carl the pudding.

One observation that argues for this identification of pair-list interpretations with conjoined questions is that overtly conjoined questions do not allow for functional answers. We cannot answer (31) by His favorite dish or Their favorite dishes, and if (30), in its pair-list reading, has the same meaning as (31), then it immediately follows that it cannot be answered with a functional term.

\subsection{Conjoined Speech Acts}

What are conjoined questions? In the theory of Groenendijk \& Stokhof (1984, 1989), the conjunction of two questions is the intersection of the partitions induced by these questions, which is again a partition, that is, a proper question. Here I would like to explore the idea that conjoined questions are conjoined speech acts, which will lead us to a more general picture, as it applies to other speech acts as well.

I consider speech acts as moves in conversational games, in the spirit of Wittgenstein (1958). I am not in a position to give anything like a formal system for conversational moves, but there are promising first suggestions, as the "algebra of social acts" developed by Merin (1994). Rather, I will make some general and hopefully uncontroversial, assumptions.

Let us assume that conversational games consist of a set of states, and transitions between those states. If $s$ is the current state in a conversational game, then 
the performance of an appropriate act A leads to a new state, $s^{\prime}$. Of course, not every act will be appropriate for a given state.

$A(s)=s^{\prime}$, if $A$ is appropriate for $s$, else $A(s)$ is undefined.

Some acts require corresponding acts; reference to these corresponding acts is part of their definition. Examples are questions and their corresponding answers, and commands and actions that carry out the commands (which need not be speech acts). I will talk of initiating acts and responding acts, respectively. The conversational states after initiating acts are characterized by the expected response. For example, if $s$ is a neutral state and $Q$ is a question act, then $Q(s)=s^{\prime}$ is a state in which a particular reaction, an answer $A$, is expected to lead back to a neutral state.

$\mathrm{A}(\mathrm{Q}(\mathrm{s}))=\mathrm{Q}\left(\mathrm{s}^{\prime}\right)=\mathrm{s}^{\prime \prime}$, where $\mathrm{Q}$ is appropriate for $\mathrm{s}$, and $\mathrm{A}$ is appropriate for $\mathrm{s}^{\prime}$.

Now it appears that speech acts in general can be conjoined. We can conjoin assertions, questions, commands, exclamations, baptisms, curses, and more.

(35) a. My dog loves chicken soup. And my cat likes chopped liver.

b. Which dish did Al make? And which dish did Bill make?

c. Eat the chicken soup! And, drink the hot tea!

d. How beautiful this is! And how peaceful!

e. I hereby baptize you John. And I hereby baptize YOU Mary.

f. You are an idiot! And you are a fool!

The conjunction of acts is obviously equivalent to the consecutive performance of those acts. What does this mean for initiating acts? In particular, what is the responding act to a conjunction of initiating acts? Obviously, a conjunction of acts that respond to each of the conjuncts of initiating act. Using "\&" as the symbol for act conjunction, this can be expressed as follows:

(36) If $\mathrm{A}(\mathrm{Q}(\mathrm{s}))$ and $\mathrm{A}^{\prime}\left(\mathrm{Q}^{\prime}(\mathrm{s})\right)$ are valid conversational moves, then $\left[A \& A^{\prime}\right]\left(\left[Q \& Q^{\prime}\right](s)\right)$ is a valid conversational move; it is equivalent to $\mathrm{A}^{\prime}\left(\mathrm{Q}^{\prime}(\mathrm{A}(\mathrm{Q}(\mathrm{s})))\right.$ and $\mathrm{A}\left(\mathrm{Q}\left(\mathrm{A}^{\prime}\left(\mathrm{Q}^{\prime}(\mathrm{s})\right)\right)\right.$.

For example, the act sequences in (37) and (38) are equivalent:
a. A: Which dish did $\mathrm{Al}$ make?
B: The pasta.
A: Which dish did Bill make?
B: The salad.

b. A: Which dish did Al make? And which dish did Bill make?

a. A: Pick up the ball!

B: [Picks up ball.]

A: Throw it to me!

B: [Throws ball to A.]

B: Al (made) the pasta, and Bill the salad.
b. A: Pick up the ball! And, throw it to me!
B: [Picks up the ball and throws ball to A.]

\subsection{Disjunction of Speech Acts?}

If speech acts can be conjoined, we would expect that they can also be disjoined. (39) is a good candidate for the disjunction of two questions.

Which dish did $\mathrm{Al}$ make or which dish did Bill make? 
But the status of such sentences is unclear. Szabolcsi (1997) judges them ungrammatical, and sentences like (40) as devices to revoke the first question and replace it by the second (or rather...). That is, we don't have a question disjunction; the linguistic device that would have this meaning is interpreted differently.

Which dish did $\mathrm{Al}$ make? Or, which dish did Bill make?

Opinions about disjoined questions like (39) vary, though. Belnap \& Steel (1976) assume that questions can be disjoined (e.g., Have you ever been to Sweden, or have you ever been to Germany?). A direct answer to such a question is one that answers at least one subquestion. Groenendijk \& Stokhof (1984) subsume such readings under choice readings. While such readings may indeed exist in natural language, and not only in the mind of trained logicians, they are considerably less natural than conjoined questions, and more readily subject to reinterpretation. (Cf. section 6 for further discussion).

What about commands? The conjoined command (41) can be understood in two ways, as illustrated by the paraphrases (41.a) and (b):

(41) Pick up the ball or pick up the racket.

a. 'Act to make true: You pick up the ball or you pick up the racket'

b. 'Pick up the ball, or pick up the racket, I don't know which.'

In (41.a), or disjoins the underlying proposition and not the commands; hence this is not an example of command disjunction. In (41.b), the speaker hasn't made up his or her mind, and the result is not a command (cf. Merin (1992) on 'weak' readings of permission sentences). Neither is a true disjunction of commands.

Consider now baptisms and curses. Clearly, (42) is not a proper baptism, and (43) is not a curse, rather a description.

(42) \#I hereby baptize you John, or I hereby baptize YOU Mary.

(43) You are an idiot, or you are a fool!

Assertions turn out not to be different. Disjunction is interpreted as a disjunction of the asserted propositions, not of the acts of assertion:

$\mathrm{Al}$ made the pasta, or Bill made the salad.

a. 'I assert: Al made the pasta or Bill made the salad.'

b. *'I assert: Al made the pasta, or I assert: Bill made the salad.'

Disjunction also has to be reinterpreted in cases like Get out or I call the police that appear to disjoin a command and an assertion but are to be interpreted as a conditional. We conclude that, while coordination is well-defined operation for speech acts, disjunction is not. Syntactic forms that look like disjunction of two speech acts typically are interpreted in special ways, e.g., by lowering the disjunction to the propositional level, or by interpreting it as replacement of the first speech act. The only exception are choice readings, to which we will return in section 7 .

The lack of a disjunction means that acts do not form a Boolean algebra. Acts certainly lack complement formation, the third Boolean operation. They form a simpler algebraic structure with just one operation, conjunction. We can reasonably assume that act conjunction is commutative ( $\left.A \& A^{\prime}=A^{\prime} \& A\right)$, at least when we dis- 
regard potential anaphoric bindings between $A$ and $A^{\prime}$. It is also idempotent (A\&A $=A)$ and associative $\left(A \&\left(A^{\prime} \& A^{\prime \prime}\right)=\left(A \& A^{\prime}\right) \& A^{\prime \prime}\right)$, hence it forms a semi-lattice.

\subsection{Restriction for Quantifiers in Questions Explained}

The analysis of pair-list interpretations as conjoined questions, and the analysis of speech act conjunction as involving a semi-lattice and not a full Boolean algrebra, explains why only universal quantifiers can scope out of speech acts. The reason is that universal quantifiers are generalized conjunctions, whereas other quantifiers cannot be reduced to conjunction (cf. Keenan \& Faltz (1985)):

a. Every boy came. $\Leftrightarrow \mathrm{Al}$ came and Bill came and Carl came.

b. A boy came. $\quad \Leftrightarrow \mathrm{Al}$ came or Bill came or Carl came.

c. No boy came. $\quad \Leftrightarrow$ Not: Al came or Bill came or Carl came.

d. Most boys came. $\Leftrightarrow \mathrm{Al}$ came and Bill came, or

Al came and Carl came, or

Bill came and Carl came.

This explains why we have robust pair-list interpretations only with universal quantifiers - they are the only ones that can be reduced to conjunction.

(46) Which dish did every boy make?

$\Leftrightarrow$ For every boy $\mathrm{x}$ : Which dish did $\mathrm{x}$ make?

$\Leftrightarrow$ Which dish did $\mathrm{Al}$ make, which dish did Bill make, and which dish did Carl make?

\#Which dish did most boys make?

$\Leftrightarrow$ For most boys $\mathrm{x}$ : Which dish did $\mathrm{x}$ make?

$\Leftrightarrow$ Which dish did Al make and which dish did Bill make, or which dish did $\mathrm{Al}$ make and which dish did Carl make, or which dish did Bill make and which dish did Carl make?

We find the same situation for other speech acts as well. Universal quantifiers (but not others) can scope out of commands, baptisms and curses:

(48) a. Confiscate every book on dinosaurs!

b. \#Confiscate most books on dinosaurs!

(49) a. I hereby baptize everyone of you John.

b. \#I hereby baptize most of you John.

(50) a. Everyone of you is a crook! (a possible curse)

b. Most of you are crooks! (not a curse, a description).

In addition to quantifiers and conjoined NPs, we find wide-scope interpretations of definite NPs that are interpreted distributively:

Which dish did the boys make?

'For each of the boys $\mathrm{x}$ : Which dish did $\mathrm{x}$ make?'

This can be analyzed as involving a distributive operator, i.e. a universal operator that quantifies over the domain given by the boys (cf. Beghelli (1997)). As a universal operator, distributivity can be defined on the basis of speech act conjunction. 


\section{An Implementation of Speech Act Quantifiers}

In this section I will show how the idea of quantification into acts as involving act conjunction can be implemented in a formal system. The problem is that the quantifier, and often also overt conjunction, does not appear where it is supposed to be. Rather, the quantifier or the conjunction are placed in argument positions:
a. Which dish did every boy make?
b. Which dish did $\mathrm{Al}$, Bill and Carl make?

For speech act conjunction, these expressions cannot be interpreted in situ, but have to scope out of the speech act operator. Let us assume the format of Stenius (1967), where an illocutionary operator combines with a sentence radical meaning (typically, a proposition) to form a speech act. Assume the basic types as in (53.a) and the general type-formation rule as in (b).

(53) a. Basic types: $e$ entities, $t$ truth values, $p(=s t)$ propositions, $a$ speech acts.

b. Derived types: If $\tau, \sigma$ are types, then $(\sigma) \tau$ is a type (the type of functions from elements of type $\sigma$ to elements of type $\tau$ ). If $\sigma$ is basic, I write $\sigma \tau$.

If $p$ is the type of sentence radicals, then the type of illocutionary operators is $p a$ (a function from propositions $p t$ to speech acts). Some examples:
a. It is raining. ASSERT( ${ }^{\wedge}$ RAINING)
$\frac{p a \quad p}{a}$
b. Get up! COMMAND $(\stackrel{\wedge}{\text { GETUP(YOU) }})$ $p a+p$

Let us assume the question representation of Hamblin (1973). The sentence radical for questions is a set of propositions, hence the type of the question operator is not $p a$, but $(p t) a$, where $p t$ is the type of sets of questions.

$$
\text { Which dish did Al make? } \frac{\frac{\operatorname{QUEST}}{(p t) a} \frac{\left(\lambda \mathrm{p} \exists \mathrm{x}\left[\mathrm{Dr}(\mathrm{x}) \wedge \mathrm{p}={ }^{\wedge} \mathrm{MA}(\mathrm{x})(\mathrm{A})\right]\right.}{p t}}{a}
$$

Speech act coordination is of type aaa: It takes two speech acts and yields a speech act. I write $\tau^{+}$for types $(\tau)(\tau) \tau$.

$$
\begin{array}{cll}
\text { Which dish did Al make } & \frac{\text { and }}{a^{+}} \quad \frac{\text { which dish did Bill make? }}{a} \\
a & a
\end{array}
$$

In $(52 . a, b)$, the conjunction is embedded in the expression that denotes the set of propositions. It cannot be interpreted as is, but must be type-lifted. This type lifting is well-known from Boolean conjunction and disjunction, cf. Partee (1983) and Keenan \& Faltz (1985). In the following example, Boolean conjunction, type $p^{+}$, is lifted to accommodate quantifiers of type $(e p) p$.

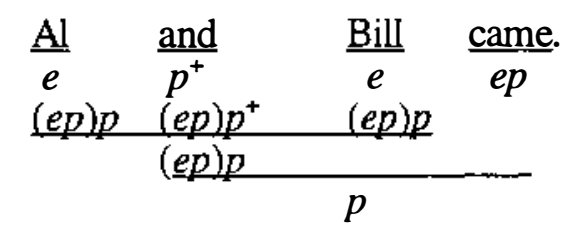

basic type assignment type lifting functional application 
Speech act conjunction can be treated in an exactly parallel fashion. For simplicity of exposition, I assume here LF movement of the conjoined NP.

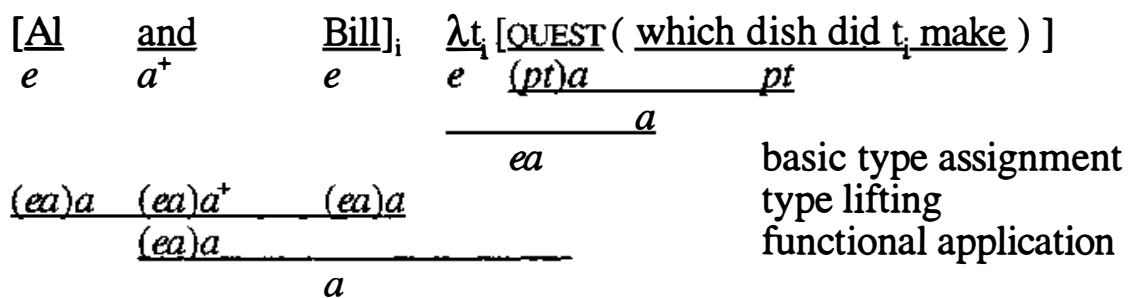

On the basis of these types we can derive the following interpretation. I use $\mathrm{b}$ as variable of type $e a$, and $\mathrm{c}, \mathrm{c}^{\prime}$ as variables of type (ea) $a$; the symbol \& stands for act conjunction, i.e. consecutive performance.

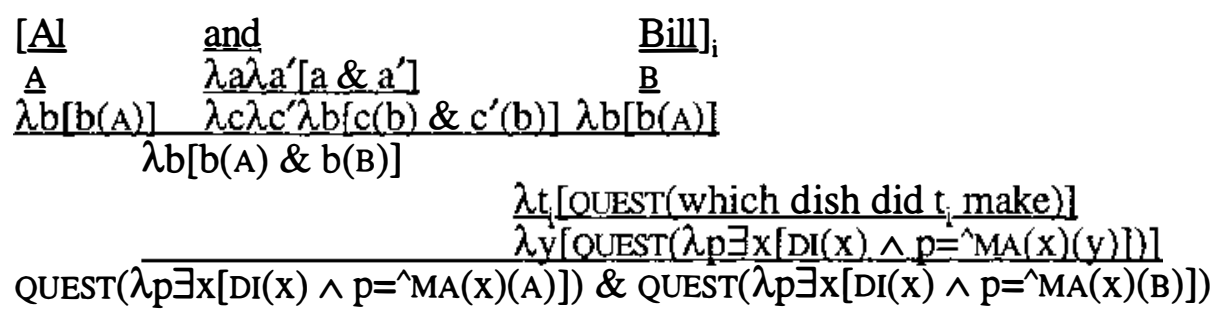

Cases involving a universal quantifier instead of a conjoined NP are treated in exactly the same fashion. Let me give here the interpretation of every boy as a quantifier that scopes out of speech acts (type $(e a) a)$. I write \&A for the conjunction of all speech acts in a set of speech acts $\mathbf{A}$. This general conjunction can be defined for finite sets $\mathbf{A}$, as $\&$ is commutative, associative and idempotent. We get the conjunction of the speech acts Which dish did y make?, where y varies over boys.

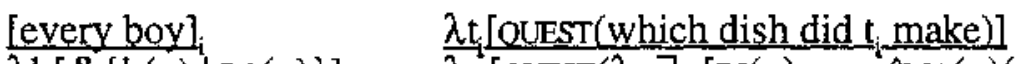

$$
\begin{aligned}
& \lambda \mathrm{b}[\&\{\mathrm{~b}(\mathrm{y}) \mid \mathrm{BO}(\mathrm{y})\}] \quad \lambda \mathrm{y}\left[\operatorname { O U E S T } \left(\lambda \mathrm{p} \exists \mathrm{x}\left[\mathrm{DI}(\mathrm{x}) \wedge \mathrm{p}={ }^{\wedge} \mathrm{MA}(\mathrm{x})(\mathrm{y})\right] \mathrm{C}\right.\right. \\
& \&\left\{\operatorname{QUEST}\left(\lambda \mathrm{p} \exists \mathrm{x}\left[\mathrm{DI}(\mathrm{x}) \wedge \mathrm{p}={ }^{\wedge} \mathrm{MA}(\mathrm{x})(\mathrm{y})\right]\right) \mid \mathrm{BO}(\mathrm{x})\right\}
\end{aligned}
$$

Why do the same linguistic devices - conjunctions, quantifiers - express both Boolean conjunction $\wedge$ and speech-act conjunction $\&$ ? There is a natural connection between the two: Conjoined speech acts can be reported by conjoined propositions, e.g. She asked what Al did and she asked what Bill did.

\section{Wide-Scope Speech Act Quantifiers as Topics}

The representations in (58) and (60) assume that speech acts are not, in general, islands for movement. But which sub-sentential expressions could scope out of a speech act? I would like to suggest that topics can do that. The following examples quite obviously involve topics scoped out of questions, commands and curses.

(61) a. As for Al, Bill and Carl, which dishes did they make?

b. The hamburger, please hand it to me.

c. This guy, he should go to hell!

Perhaps topics even have to scope out of speech acts. Topic selection is a speech act itself, an initiating speech act that requires a subsequent speech act, like an assertion, question, command, or curse about the entity that was selected. 
There is evidence that the quantifiers that scope out of speech acts are topical. First, observe that we do not find wide scope for quantifiers that are in focus. This is as expected, as the topic cannot be the main focus of a sentence.

Q: Which dish did EVERYONE make?

A: \#Al the pasta, Bill the salad, and Carl the pudding.

Second, we have seen that quantifiers in subject position facilitates widescope readings, in contrast to object quantifiers (cf. (1) vs. (3)). This is not astonishing, as subjects are prototypical topics (cf. e.g. Chafe (1976)). Furthermore, it has been observed by Beghelli (1997) that indirect objects allow for wide-scope intepretation more easily than direct objects, as in (63). Also, Kim \& Larson (1989) noticed that objects of psych verbs allow for wide-scope interpretation, cf. (64). The plausible reason is that indirect objects and the object of psych verbs are animate, and animate NPs are more likely topical (cf. Comrie (1981) p. 197ff.).

Q: Which painting did you show to every boy?

A. To Al, the Picasso, to Bill, the Klee, and to Carl, the Mondrian.

Q: Which painting impressed every boy most?

A: Al, the Picasso, Bill, the Klee, and Carl, the Hundertwasser.

We have seen that quantifiers headed by each in general allow for wide scope, cf. (25). This can be explained by their presuppositional nature; each boy presupposes a given set of boys. As topics, in general, presuppose the existence of an entity or a set, this helps explain why these quantifiers can have wide scope. (cf. Lambrecht (1994) p. 155f.).

Which boy made each dish / each of those dishes?

Another observation, due to Stechow (1990), is that across-the-board extraction of the quantifier is impossible. This can be explained by the fact that sentences cannot have more than one topic.

Q: Which dish did every boy like and every girl hate?

A: \#Al, the pasta, Bill, the pudding, Ann, the salad, and Beth, the soup.

Szabolcsi (1997) observes that sentences like (67.a) are more easily interpreted as a pair-list question than sentences like (67.b). A plausible reason for this is that singular which-phrases and what-phrases are more likely topical than who or plural what-phrases.

a. Who / which boys did every dog bite?

b. Which boy / what boy did every dog bite?

It appears that the assumption that only topics can scope out of speech acts makes a number of valid predictions and is well justified on theoretical grounds.

\section{The Nature of Choice Readings}

Let me return to the subject of choice readings, which, I have argued, are marginally possible, even though they are not based on a universal quantifier. This notion has been applied to two types of questions, pair-list readings with nonuniversal quantifiers (68) and disjoined questions (69): 
Which dish did two boys make?

Which dish did Al make or which dish did Bill make?

One way to interpret (68) is to assume that indefinites can marginally be used as topics, with the interpretation that leaves a choice to the hearer to pick an instance of a class. The sentence then is interpreted distributively, that is, by a universal quantifier based on speech act conjunction (cf. (51)):

Which dish did two boys make?

'For two boys that you select: Which dish did each of these boys make?'

Notice that this reading requires that the indefinite NP is destressed, which is characteristic for topical expressions. This analysis correctly predicts that these choice readings are considerably worse with quantifiers like more than two boys or less than seven boys, which are not as easily interpreted as topical, presumably because they involve focus-sensitivity (cf. Krifka (to appear)).

What about the other type of choice readings, disjoined questions? While they are in many cases reinterpreted as not involving disjunction of questions (cf. section 3.3), there are plausible candidates for truly disjoined questions:

(71) a. Where is your father or where is your mother?

b. Where is your father or your mother?

Notice that (71.a,b) can be fully answered by (My father or my mother are) in the kitchen; answers like My father is in the kitchen are, technically, overinformative answers. This suggests that such questions are not disjoined speech acts, but single speech acts based on a disjoined question radical. If question radicals are sets of propositions, and disjunction is basically an operation for proposition, then it should be interpreted here as element-wise disjunction:

If $\mathrm{Q}, \mathrm{Q}^{\prime}$ are two question radicals (type $p t$ ), then $\mathrm{Q} \vee \mathrm{Q}^{\prime}=\left\{\mathrm{p} \vee \mathrm{p}^{\prime} \mid \mathrm{p} \in \mathrm{Q}, \mathrm{p}^{\prime} \in \mathrm{Q}^{\prime}\right\}$, which is equivalent to $\lambda p^{\prime \prime} \exists p \exists p^{\prime}\left[\left[p^{\prime \prime}=p \vee p^{\prime}\right] \wedge Q(p) \wedge Q^{\prime}\left(p^{\prime}\right)\right]$

But then we could also interpret conjunction at the level of question radicals, as the dual notion of disjunction. And we could interpret quantifiers based on these operations, such as the universal quantifier.

$$
\begin{aligned}
& \text { which dish did every boy make } \\
& \text { a. (given that } \mathrm{Al} \text {, Bill, Carl are the boys): } \\
& \left\{p \wedge p^{\prime} \wedge p^{\prime \prime} \mid p \in \lambda p \exists x\left[D I(x) \wedge p={ }^{\prime} M A(x)(A)\right],\right. \\
& \mathrm{p} \in \lambda \mathrm{p} \exists \mathrm{x}[\operatorname{DI}(\mathrm{x}) \wedge \mathrm{p}=\wedge \mathrm{MA}(\mathrm{x})(\mathrm{B})],
\end{aligned}
$$

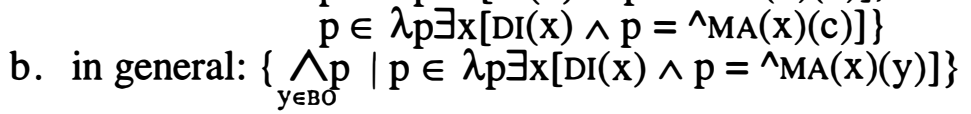

Each proposition in this set will specify, for each boy, which dish this boy made. This is similar to Groenendijk \& Stokhof's treatment, cf. the left-hand side of (14). But one important difference is that the results need not be partitions: The original question radicals are not necessarily partitions, and combinations based on disjunction will not yield partitions, even if the original question radicals were. 
But if we could interpret universal quantifiers in this way, we also could interpret other quantifiers based on Boolean operations. The question, then, arises, why pair-list readings cannot be traced back to quantification over question radicals. One plausible answer is that disjunction and conjunction of question radicals are cognitively difficult operations, to be avoided if possible, especially when the questions are not given individually but indirectly, by way of a quantifier. It cannot be avoided for disjoined questions, but it can be avoided for conjoined questions and universally quantified questions, which are more easily interpreted as involving speech act conjunction.

One important difference between quantifying into question acts and quantifying into question radicals is that in the latter case the quantified NP need not be topical. In (71.b), your father or your mother need not be destressed in the same way as quantifiers with scope over question acts are destressed (cf. (62)). This suggests that the ways how the wide scope readings arise are indeed different.

\section{Embedded Questions}

Let us turn now to embedded questions. Karttunen (1977) pointed out several types of embedding verbs that show distinct semantic behavior; Groenendijk \& Stokhof (1984) identified two broad classes which they call extensional (e.g., know, tell, find out) and intensional (e.g., ask, wonder, want to find out). With respect to quantification into questions, Szabolcsi (1993) discovered that wide-scope interpretations of non-universal quantifiers that are not available in root questions and in questions embedded by intensional verbs become available for extensional verbs (judgements are for pair-list readings):

(74) \#Which dish did most boys make?

(75) a. \#Doris wondered which dish most boys made.

b. \#Doris asked which dish most boys made.

c. \#Doris wants to find out which dish most boys made.

(76) a. Doris knows which dish most boys made.

[She knows that $\mathrm{Al}$ made the pasta and Bill the salad.]

b. Doris found out which dish most boys made.

c. Doris told Elizabeth which dish most boys made.

One promising way to explain this difference assumes that only intensional verbs embed a question act. As there is no pair-list interpretation of the question act (74.a), there is also no corresponding pair-list interpretation for the embedded question acts in $(74 . b, c)$. Extensional verbs, on the other hand, embed not a question act (type $a$ ), but a question sentence radical (type $p t$ ).

(77) a. Doris wondered [QUEST [which dish Bill made]]

b. Doris knows [which dish Bill made]

This distinction is be motivated by the following paraphrases (cf. Szabolcsi 1993):

(78) Doris wondered which dish $\mathrm{Al}$ made. $\Leftrightarrow$

Doris wants to know the answer to the question: Which dish did Al make?

(79) Doris found out which dish $\mathrm{Al}$ made. $\Leftrightarrow$

Doris found out which propositions in the sentence radical 'which dish did Al make' are true. 
Independent evidence for this distinction comes from the following syntactic differences, which show that intensional verbs, in contrast to extensional verbs, can subcategorize for root questions that show syntactic inversion.

(80) Which dish did Al make, Doris wondered / asked / wanted to find out.

(81) *Which dish did Al make, Doris found out / knew / told Elizabeth.

The notion of embedded speech acts may be considered problematic. However, notice that there are bona fide cases of embedded speech acts, e.g. direct speech and embedded performatives (cf. Lee (1975)).

a. Doris said: "Al made the pasta."

b. I regret [that I must inform you [that you are hereby dismissed]].

Assuming that intensional verbs embed question acts does not immediately explain why we cannot have wide-scope non-universal quantifiers. The quantifier could scope over the embedding sentence, which is of an appropriate type.

$$
\frac{\frac{\text { most boys }}{(e p) p} \frac{\frac{\lambda t}{e}}{\frac{e}{e}} \frac{\text { Doris }}{a e p} \frac{\text { wondered }}{e p} \frac{\text { [QUEST }}{(p t) a} \frac{\text { [which dish t made]]] }}{p t}}{p}
$$

There are at least two ways to explain why the reading represented by (83) does not obtain. One is assuming cyclic quantifier raising, with the condition that the quantifier must be interpretable at every possible intervening scope position (presumably, every clause).

a. most boys $\mathrm{s}_{\mathrm{i}}$ [Doris knows [ $\mathrm{t}_{\mathrm{i}}^{\prime}$ [which dish $\mathrm{t}_{\mathrm{i}}$ made]]].

b. most boys ${ }_{i}$ [Doris wonders [ $\mathrm{t}_{\mathrm{i}}^{\prime}$ [QUEST [which dish $\mathrm{t}_{\mathrm{i}}$ made]]]]

Here, (84.b) is out because the quantifier most boys could not be interpreted at $\mathrm{t}_{\mathrm{i}}{ }^{\prime}$, as it is not defined for arguments of the type of question acts, in contrast to the universal quantifier every boy. But most boys could be interpreted at $\mathrm{t}_{\mathrm{i}}^{\prime}$ in (84.a): Question radicals are sets of propositions, that is, they are construed from entities for which Boolean functions are defined (cf. section 6), even though this may not be a preferred option.

One potential problem for this explanation is that it makes us expect scope interactions between the embedded quantifier and quantifiers in the upstairs clause. But they appear to be absent (cf. Moltmann \& Szabolcsi (1994)). There is no interpretation for (85) in which every boy scopes over some girl:

Some girl or other knew which dish every boy made.

The second explanation assumes that the wide-scope reading that we saw with extensional verbs is generated by type-lifting of the embedded question. Something like this has been proposed by Moltmann \& Szabolcsi (1994) to explain the lack of wide-scope readings for (85). We have the following type assignments: 


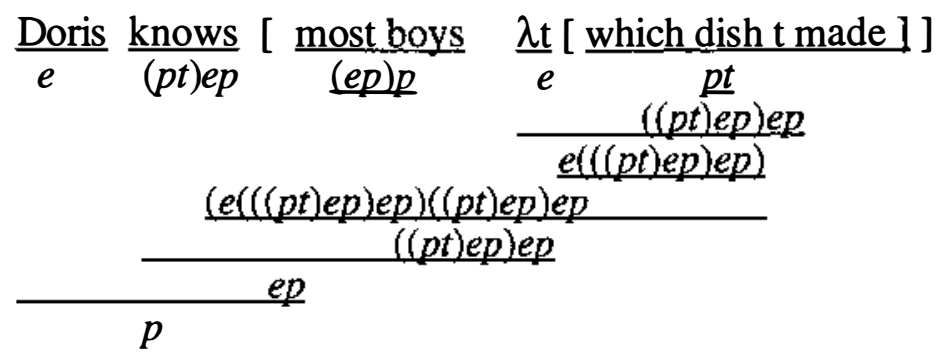

type lifting abstraction type lifting

The first type lifting changes the question radical so that it can scope over the embedding verb. The second changes the quantifier to a type that accomodates the lifted question meaning. The type assignments in (86) allow for the derivation in (88). The quantifier most is interpreted by the constant MOST, defined in (87):

$$
\begin{aligned}
& \operatorname{MOST}(\mathrm{P})\left(\mathrm{P}^{\prime}\right)=\lambda \mathrm{i}\left[\#\left\{\mathrm{x} \mid \mathrm{P}(\mathrm{x})(\mathrm{i}) \wedge \mathrm{P}^{\prime}(\mathrm{x})(\mathrm{i})\right\} / \#\{\mathrm{x} \mid \mathrm{P}(\mathrm{x})(\mathrm{i})\}>1 / 2\right] \\
& \text { Doris knows [most boys } \underline{\lambda t} \text { [which dish tmade]] } \\
& \mathrm{D} \quad \mathrm{KN} \quad \operatorname{MOST}(\mathrm{BO}) \quad \lambda \mathbf{p} \exists \mathbf{x}\left[\operatorname{DI}(\mathbf{x}) \wedge \mathbf{p}={ }^{\top} \mathbf{M A}(\mathbf{x})(\mathbf{y})\right] \\
& \lambda \mathrm{k} \lambda \mathrm{z}\left[{ }^{\wedge} \mathrm{k}\left(\lambda \mathrm{p} \exists \mathbf{x}\left[\mathrm{DI}(\mathbf{x}) \wedge \mathrm{p}==^{\wedge} \mathrm{MA}(\mathbf{x})(\mathbf{y}) \mathrm{I}\right)(\mathrm{z})\right]\right. \\
& \overline{\lambda y \lambda} \mathrm{k} \lambda \mathrm{z}\left[{ }^{\wedge} \mathrm{k}\left(\lambda \mathrm{p} \exists \mathrm{x}\left[\mathrm{DI}(\mathrm{x}) \wedge \mathrm{p}={ }^{\wedge} \mathrm{MA}(\mathrm{x})(\mathrm{y})\right]\right)(\mathrm{z})\right] \\
& \lambda \mathrm{q} \lambda \mathrm{k} \lambda z[\operatorname{MosT}(\mathrm{BO})(\lambda \mathrm{y}[\mathrm{g}(\mathrm{y})(\mathrm{k})(\mathrm{z})])] \\
& \lambda \mathrm{k} \lambda z\left[\operatorname{MOST}(\mathrm{BO})\left(\lambda \mathrm{y}\left[\mathrm{k}\left(\hat{\alpha} \mathrm{p} \exists \mathrm{X}\left[\mathrm{DI}(\mathrm{x}) \wedge \mathrm{p}==^{\wedge} \mathrm{MA}(\mathrm{x})(\mathrm{y})\right]\right)(\mathrm{z})\right]\right)\right] \\
& \operatorname{MOST}(\mathrm{BO})\left(\lambda y\left[{ }^{\wedge} \mathrm{KN}\left(\lambda \mathrm{p} \exists \mathrm{x}\left[\mathrm{DI}(\mathrm{x}) \wedge \mathrm{p}=^{\wedge} \mathrm{MA}(\mathrm{x})(\mathrm{y})\right]\right)(\mathrm{D})\right]\right)
\end{aligned}
$$

It does not immediately follow that sentences like (75) are out. In the derivation (88), the quantifier is applied to the lambda abstraction over the embedded verb, and this is of the right type even if the verb embeds a question act. Type assignments and type liftings as in (89) would lead to representations as in (90), which are fine because the quantifier can be defined by Boolean operations; it is the same as in (88).

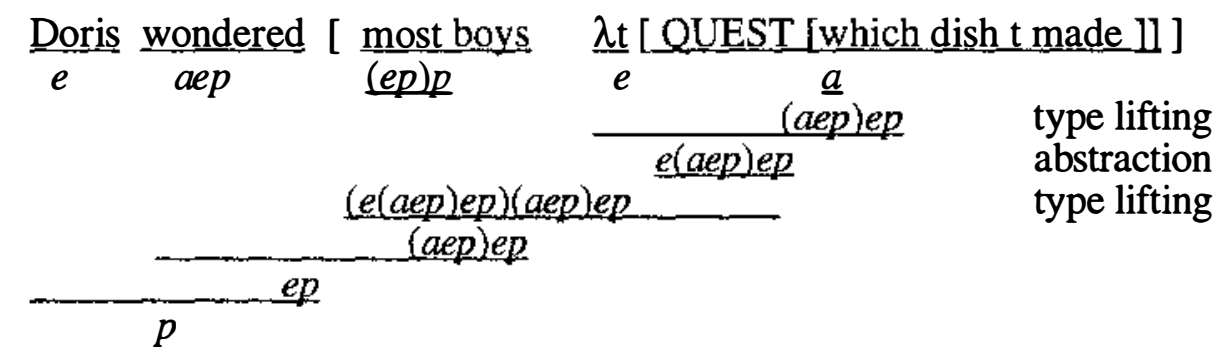

$$
\operatorname{MOST}(B O)\left(\lambda y\left[{ }^{\wedge} \operatorname{WONDER}\left(\operatorname{QUEST}\left(\lambda \mathrm{p} \exists \mathrm{x}\left[\operatorname{DI}(\mathrm{x}) \wedge \mathrm{p}=^{\wedge} \mathrm{MA}(\mathrm{x})(\mathrm{y})\right]\right)\right)(D)\right]\right)
$$

One way to exclude (89) is to assume that speech acts cannot undergo type-lifting. They are complete expressions that cannot be turned to functions, except by the process of abstraction over a variable. But this is a mere stipulation at this point.

If this explanation is right, then we should see similar results for coordinated embedded questions. In particular, conjoined questions should allow for a wide-scope interpretation, but disjoint question shouldn't. This is precisely what Szabolcsi (1997), who does not allow for disjoined root questions, finds:

(91) a. Doris wondered which dish $\mathrm{Al}$ made and $/$ ?"or which dish Bill made.

b. Doris knows which dish $\mathrm{Al}$ made and/or which dish Bill made. 
But recall that we found disjoined questions at least marginally possible (cf. section 6). Also, notice that (91.a) can be interpreted with or if it is strongly stressed. It is unclear why stress should change the availability of the readings.

We have discussed two possible explanations of why questions embedded by extensional verbs may behave differently in terms of wide-scope quantification. Both approaches where stipulative to a certain extent - the first in assuming cyclic movement, were each landing site must be a possible site for interpretation, the second in assuming a principle that speech act operators cannot undergo typelifting. The choice between those approaches will depend on independent evidence we can find for them.

\section{Conclusion}

In this paper, I have argued that quantification into question acts is possible for universal quantifiers, as these quantifiers are based on conjunction, an operation that is defined for speech acts. While Groenendijk \& Stokhof $(1984,1989)$ also make a natural distinction between quantification into questions with universal quantifiers vs. existential quantifiers, the same restriction applies for other types of speech acts as well. I have developed a type system that can capture quantification into question acts. In addition to this main topic, I have argued that expressions that scope out of speech acts must be topic, which explains a number of additional observations. I have also discussed the marginally available choice questions and embedded questions, which, depending on the embedding verb, may allow for quantification into questions.

\section{Acknowledgements}

Thanks to Greg Carlson, Sandra Chung, Edit Doron, Mark Gawron, Jeroen Groenendijk, Terence Parsons, Barbara Partee and Anna Szabolcsi for stimulating discussion at the conference.

\section{References}

Barwise, Jon \& Robin Cooper. 1981. Generalized quantifiers and natural language. Linguistics and Philosophy 4, 159-219.

Beghelli, Filippo. 1997. The syntax of distributivity and pair-list readings. In Anna Szabolcsi (ed.), Ways of scope taking 349-408. Dordrecht: Kluwer.

Belnap, Nuel D. \& Thomas B. Steel. 1976. The logic of questions and answers. New Haven: Yale University Press.

Chafe, William. 1976. Givenness, contrastiveness, definiteness, subjects, topics and point of view. In Charles N. Li (ed.), Subject and Topic 27-55. New York: Academic Press.

Chierchia, Gennaro. 1993. Questions with quantifiers. Natural Language Semantics 1, 181-234.

Comrie, Bernard. 1981. Language universals and linguistic typology. London: Blackwell.

Engdahl, Elisabet. 1985. Interpreting questions. Cambridge: Cambridge University Press.

Groenendijk, Jeroen \& Martin Stokhof. 1984. Studies on the semantics of questions and the pragmatics of answers. Doctoral Dissertation, University of Amsterdam. 
Groenendijk, Jeroen \& Martin Stokhof. 1989. Type-shifting rules and the semantics of interrogatives. In Gennaro Chierchia, Barbara H. Partee \& Raymond Turner (eds.), Properties, types and meanings. Vol. 2: Semantic issues 21-69. Dordrecht: Kluwer.

Hamblin, C.L. 1973. Questions in Montague grammar. Foundations of Language 10, 41-53.

Karttunen, Lauri. 1977. Syntax and semantics of questions. Linguistics and Philosophy 1, 3-44.

Keenan, Edward \& Leonard M. Faltz. 1985. Boolean semantics for natural language. Dordrecht: Reidel.

Kim, Young-joo \& Richard Larson. 1989. Scope interpretation and the syntax of psych-verbs. Linguistic Inquiry 20, 681-688.

Krifka, Manfred. to appear. At least some determiners aren't determiners. In Ken Turner (ed.), Current research in the semantics/pragmatics interface. Amsterdam: Elsevier.

Lambrecht, Knud. 1994. Information structure and sentence form. Topic, focus, and the mental representation of discourse referents. Cambridge: Cambridge University Press.

Lee, Chungmin. 1975. Embedded performatives. Language 51, 105-108.

Levinson, Stephen C. 1983. Pragmatics. Cambridge: Cambridge University Press.

Liu, Feng-hsi. 1990. Scope dependency in English and Chinese, University of California, Los Angeles.

Merin, Arthur. 1992. Permission sentences stand in the way of Boolean and other lattice-theoretic semantices. Journal of Semantics 9, 95-162.

Merin, Arthur. 1994. Algebra of elementary social acts. In Savas L. Tsohatzidis (ed.), Foundations of speech act theory. Philosophical and linguistic perspectives 234-266. London: Routledge.

Moltmann, Friederike \& Anna Szabolcsi. Year. Scope interactions with pair-list quantifiers. Mercé González (ed.), NELS 24, Vol. 2 381-395: GLSA Publications, University of Massachusetts at Amherst.

Pafel, Jürgen. 1999. Interrogative quantifiers within scope. Linguistics and Philosophy.

Partee, Barbara; Rooth, Mats. 1983. Generalized conjunction and type ambiguity. In R. Bäuerle, Chr. Schwarze \& A. von Stechow (eds.), Meaning, use and interpretation of language 361-383. Berlin: de Gruyter.

Ross, John R. 1970. On declarative sentences. In R.A. Jacobs \& P.S. Rosenbaum (eds.), Readings in English Transformational Grammar 222-272. Waltham, Mass.: Ginn \& Co.

Stechow, Arnim von. 1990. Layered traces, $M S$., Tübingen.

Stenius, E. 1967. Mood and language game. Synthese 17, 254-274.

Szabolcsi, Anna. Year. Quantifiers in pair-list readings and the non-uniformity of quantification, Ninth Amsterdam Colloquium 645-664: ILLC/University of Amsterdam.

Szabolcsi, Anna. 1997. Quantifiers in pair-list readings. In Anna Szabolcsi (ed.), Ways of scope taking 311-347. Dordrecht: Kluwer.

Wittgenstein, Ludwig. 1958. Philosophische Untersuchungen. London: Basil Blackwell. 